\title{
AULA INVERTIDA EN EL \\ PROGRAMA DE NEGOCIOS
}

\section{INTERNACIONALES \\ DEL POLITÉCNICO \\ GRANCOLOMBIANO

Uno de los retos más importantes dentro de las aulas de clase es llegar a los estudiantes de manera más dinámica, con clases orientadas a la formación integral y con un sentido de práctica más estructurado, de tal forma que no sean esas clases donde se imparte conocimiento sino, por el contrario, espacios de formación que claramente aportan de manera significativa al aprendizaje colectivo.

La educación tradicional ha estado en cuestionamiento por la forma en la cual se otorgan conocimientos memorísticos que impiden el desarrollo de emprendimientos, la iniciativa en ideas y en líderes capaces de resolver problemas. De la manera tradicional se está viendo estudiantes que repiten lo que el docente les dice, y el interés se pierde; los alumnos solamente están resguardados por la nota y el pasar la asignatura, que en definitiva es lo que mueve al estudiante.

4 Magister en negocios internacionales. Es Decana de la facultad de Ciencias Administrativas, Económicas y Contables de la Institución Universitaria Politécnico Grancolombiano

5 Magister en educación. Es Profesora de Tiempo completo asistente en la Institución Universitaria Politécnico Grancolombiano. 


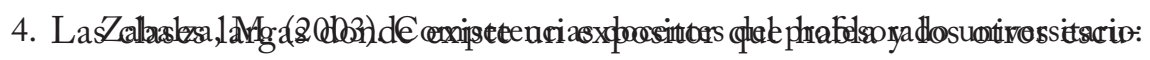

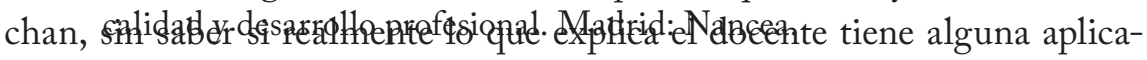
ción o lógica.

Las clases se convierten en recintos donde existen expositores y receptores, no hay intercambio de conocimiento y solo existe una vía que la evaluación reafirma con mediciones que no consolidan el proceso de enseñanzaaprendizaje.

El objetivo de esta investigación es realizar un piloto de aplicación del modelo de aula invertida, usando como metodología cualitativa la recolección documental y un estado del arte, que luego de la inspección de más de 321 documentos y mediante selección, permita establecer coincidencias y puntos de vista sobre la metodología barrido que se hace en Scopus y Emerald utilizando Medeley y Google académico. Posteriormente se va a revisar datos de evaluación, como dos focus group con el fin de evidenciar lo bueno y lo malo de este pilotaje.

En definitiva, se trata de probar alternativas didácticas y uso de las tecnologías de la información y comunicación, un acercamiento a formas de enseñanza que permitan explorar y dinamizar habilidades y competencias enfocadas a un logro definitivo de la asignatura de Negocios y relaciones internacionales.

Se va a realizar en dos cursos presenciales de Negocios Internacionales: el grupo A, de 46 estudiantes, y el grupo B, de 39 estudiantes, aplicando esta metodología y evaluando la metodología de aula inversa.

\section{EL AULA INVERTIDA, DEFINICIONES Y EJEMPLOS}

El aula al revés o invertida es una idea que se da precisamente con miras a maximizar el tiempo que se utiliza en el aula de clase, extendiendo los tiempos en los encuentros mediante el apoyo de las tecnologías de información. 
Según Aaron (2014, pág. 19): "Dar la vuelta a la clase establece una estructura con la cual se asegura que los alumnos reciben una educación personalizada, diseñada a la medida de sus necesidades individuales”.

La nueva generación de los estudiantes es cada vez más afín a la tecnología, con estructuras mentales totalmente diferentes a la educación tradicional. Los chicos constantemente se preguntan: ¿esto para qué sirve, esto qué me está enseñando como aporte en mi formación y cómo lo voy a usar en el futuro trabajo?

Existen, entonces, los docentes que se cuestionan sobre sus propias enseñanzas, o simplemente docentes que responden 'pues esto es lo que hay y ya', generando inconformismo en el estudiante y aún más preguntas sobre la aplicación práctica de los contenidos ofrecidos en las aulas (Leupin, 2016). Por otra parte, está el resultado del aprendizaje diferencial en las universidades, orientado al futuro laboral, con una didáctica realmente estructurada para el aprendizaje y su aplicación (Jancsó, 2016).

\section{Es importante señalar que aunque con este método pedagógico el alumno trabaja de forma autónoma, nunca lo hace solo porque el profesor actúa de guía en su proceso de aprendizaje, seleccionando los contenidos que debe estudiar, asimilar y retener, poniéndolos a su disposición a través de diver- sos medios (Albaladejo, 2013, pág. 3).}

La idea es no dejar al estudiante nunca solo, y lo contrario, aprovechar las aplicaciones y la tecnología como eje central del proceso de formación. No se trata solo de dejar unos vídeos y organizar actividades conexas desde la didáctica. El aula invertida implica acercarse al estudiante y empezar a generar procesos de innovación en la forma de hacer la clase y también de recibirla; los resultados académicos deben dar un vuelco total (Lacleta, 2015) (Bourdieu, 2016).

Estudios como el de Del Pino, Prieto y Prieto (2016), aplicado a la ingeniería, cuestiona la educación tradicional y da un aporte fundamental a una práctica que maximiza el tiempo y brinda acceso directo a las competencias de los estudiantes. Estos autores lo realizaron para una asignatura específi- 
ca, tal como es la idea e intención de esta investigación, y complementado con herramientas tecnológicas propias de los jóvenes actualmente.

Talbert (2015), por ejemplo, es un autor que ofrece una enorme referencia en la forma de enseñar matemáticas y cómo se debe abordar el conocimiento y el aprendizaje en estos aspectos. La herramienta de YouTube fue fundamental en el desarrollo del aula inversa.

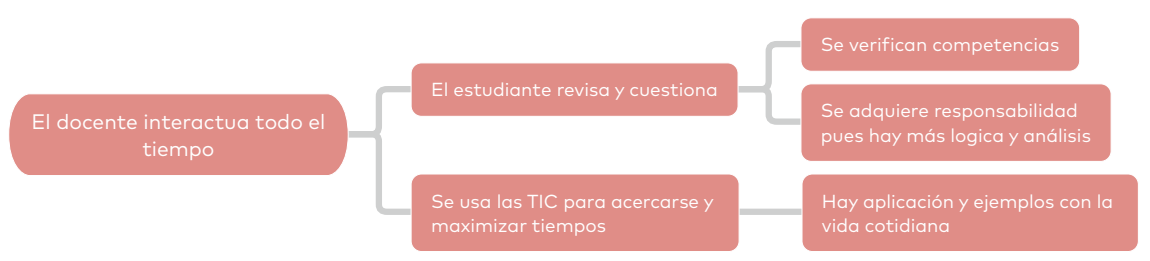

llustración 1: El sistema de aula invertida

Fuente: elaboración propia, 2017.

Para Albaladejo (2013, pág. 15), "la idea básica inherente a este modelo educativo sería la de promover que el alumno trabaje por sí mismo y fuera del aula los conceptos teóricos a través de diversas herramientas que el docente pone a su alcance, principalmente vídeos o podcasts grabados por su profesor".

Pero no cualquier vídeo por salir del paso. Se trata de mezclar la pedagogía con la explicación, vídeos y podcast cortos que motiven al estudiante a conocer y a seguir investigando; esta es la clave de la interacción: tener un lenguaje que los estudiantes quieran escuchar, tal como lo enfatiza en varios estudios el Tecnológico de Monterrey (TEC, 2014), institución precursora en la dinámica de nuevos métodos en el aula: formación completa, no que sature al estudiante con conocimiento que se acabe o se aprenda en un tiempo determinado y que no tenga aplicación alguna.

La aplicación del aula inversa depende también de retos pedagógicos y de llevar a los jóvenes a espacios interactivos de búsqueda, interés y de análisis colaborativo, de manera práctica y organizada. 


\section{EL AULA INVERSA COMO ESENCIAL PARA APROVECHAR LAS TIC}

El aula inversa o invertida parte del desarrollo pedagógico constructivista basado en experiencias significativas. Esta es una herramienta didáctica que aporta a los estudiantes un método diferente de entender y verificar la realidad de la educación, dejando de lado aprendizajes memorísticos y rompiendo esquemas, captando su atención y en busca de un perfil profesional más competitivo.

Acercamientos teóricos como los de Vidal y Morales (2016), ejemplifican claramente la metodología y la manera de organizar el tiempo en el que los estudiantes pueden ver vídeos y utilizar herramientas tecnológicas que los capaciten, al mismo tiempo que van generando estos hábitos.

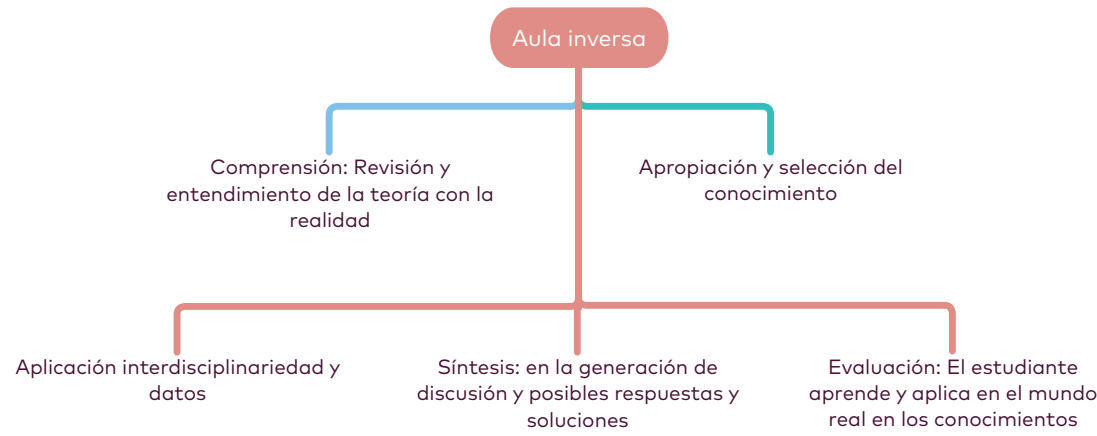

Ilustración 2: Aula inversa desde un enfoque didáctico

Fuente: : elaboración propia, basada en Vidal y Morales (2016).

El uso de las nuevas metodologías en las clases presenciales se convierte en llevar procesos de innovación y creatividad a las aulas, donde no exista encierro, sino que, al contrario, sea un gusto para el estudiante apasionarse por nuevos enfoques y nuevas formas de ver la educación.

Existen estudios que apoyan las metodologías sobre aula inversa o invertida. Entre los ejemplos de este cambio desde la raíz están Ruíz, Sánchez y Sánchez (2014), que hablan sobre la flexibilización en las aulas como una fuerte necesidad, para no seguir encerrando a los estudiantes en un ejercicio 
unidireccional. Igualmente, Mosquera Cucalón (2012) resalta aún más el papel constructivo y la relación entre los docentes y estudiantes, de manera similar al estudio realizado por Griffiths (2016), quien enfoca todo al aprovechamiento de las habilidades y las competencias de los alumnos, teniendo en cuenta a cada uno de ellos y en definitiva a sus habilidades, así como su forma de aprender y aprehender. Por su parte, Ramírez (2017) complementa la información y va más allá, pues propone una reforma desde el currículo y el micro currículo, pero el inicio desde una asignatura es esencial como piloto.

Blasco (2016) es reiterativo en asumir una relación docente y estudiante, y aporta nuevas metodologías enfocadas a una buena clase. No se trata de la clase más excéntrica, sino aquella que otorgue valor al estudiante, le dé un sentido mayor al proceso de enseñanza aprendizaje, siendo muy cuidadosos con las herramientas didácticas, pues el aprendizaje debe ser completo, complementario y darle un eje al sentido de la enseñanza.

\section{LA ASIGNATURA DE NEGOCIOS Y RELACIONES INTERNACIONALES, PILOTAJE CLASE INVERSA.}

Da Silva López, Pedrosa-de-Jesús y Watts (2016) señalan la importancia de la web 2.0 tanto para los docentes como para los estudiantes. Este tema es esencial, pues la tecnología es inevitable y cada vez más dinámica, por tanto, no se debe esconder, sino que todos debemos adaptarnos de manera directa.

Desde el campo de los negocios todo ha evolucionado: la forma y los métodos de consumo, la segmentación de los mercados y la misma cultura de hacer transacciones comerciales se ha modificado gracias a la tecnología. Ahora bien, las aulas de clase de negocios siguen siendo las mismas: un orador y unos receptores. Móviles apagados, portátiles cerrados, tabletas guardadas; nada de tecnología, teniendo tanta afuera, hace que los estu- 
diantes se sientan relegados de los procesos nuevos y simplemente se sientan apartados de la actualidad y de la comunicación.

Luján-Mora (2013), por ejemplo, enfatiza en didácticas de empoderamiento del conocimiento enfocado en el estudiante, dándole mayor apropiación y responsabilidad frente a la temática, que se puede dividir en subtemas. Este espacio debe generar una amplia investigación conjunta, con liderazgo del (o los) estudiante(s) experto(s), lo cual facilitará el proceso de enseñanza.

Esta participación activa se enfoca en la competencia argumentativa y comunicativa que todo estudiante debe desarrollar, por tanto, el aula invertida es solamente una herramienta con muchas aristas y didácticas para su desarrollo.

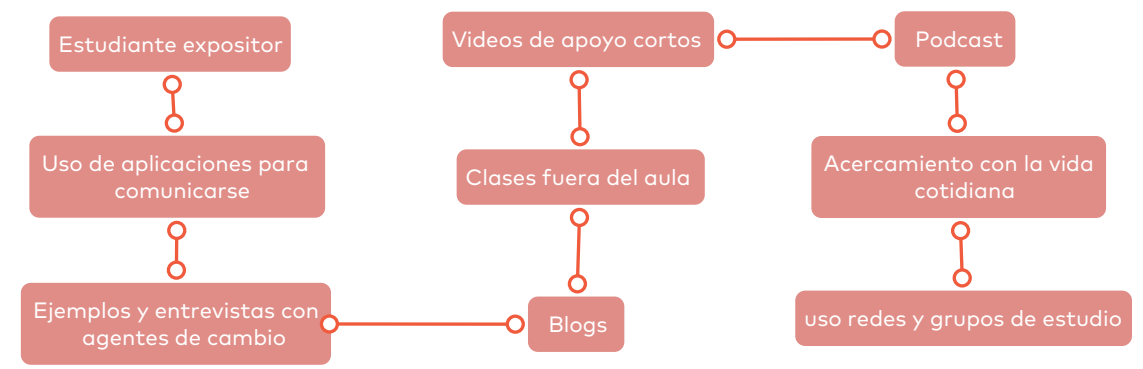

Ilustración 3: Herramientas en aula invertida

Fuente: elaboración propia, 2017.

(Sánchez Rodríguez, 2014) (Blasco A. C., 2016) (Prieto Lobato, 2017) El cambio de paradigma entonces no solo es desde lo experimental hay que hacerlo estructuralmente, por ejemplo no es dejar estas actividades y ya el reto es enganchar al estudiante para que realice trabajos y tareas propias de la temática de la clase, los videos por tanto deben ser cortos explicativos y muy dinámicos para evitar la pérdida de interés por parte de los estudiantes.

Las posibilidades también son retadoras no todos pueden pensar que esta nueva metodología es buena y consideran que el método tradicional es mejor que lo nuevo es evidente en (Gálvez, 2015) de igual manera enfatiza 
en el grado de responsabilidad e incremento de carga en el docente pues requiere mayor personalización para relazar el método como se quiere.

Pero en la educación hay que arriesgarse evidentemente se requieren perfiles que realmente apoyen los procesos productivos de los países, para el programa de Negocios Internacionales del Politécnico Grancolombiano es muy importante realizar un pilotaje que empiece también a cuestionar los procesos tradicionales y en definitiva aporte de manera real al proceso de formación de los estudiantes.

Una de las ventajas que se tienen en la universidad es la apertura a las nuevas tecnologías de la información, la institución se preocupa por contar con equipos e instalaciones cómodas, igualmente es pionera en educación virtual por tanto se cuenta con videos y con recursos tecnológicos que permiten el desarrollo de clases interesantes que puedan incluir el modelo de clase inversa. (Angelini, 2012) (Fernández-Mesa, 2016)

Por ejemplo, enfatiza sobre la formación docente con mucha pedagogía, esto apoya la mencionada crítica de que no cualquiera puede hacer clase, la sola disciplina no basta, se requiere de experiencia y de estudios en pedagogía.

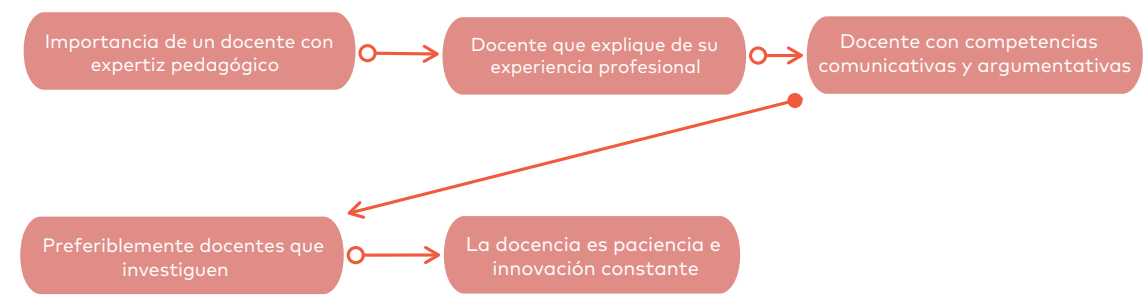

llustración 4: El docente idea para aula invertida

Fuente: elaboración propia 2017.

Para Sobrino Morrás (2014), el tema va más allá: se parte del constructivismo al conectivismo, desde lo bueno de la tecnología; el aula invertida requiere de los espacios, de los docentes y de los estudiantes, que ya traen el chip tecnológico y que algunas veces se coarta por parte de los profesores. 
La educación y el conocimiento son humildad, una frase frecuente que se queda solo en palabras, centrados en la ineficiencia. Esto mismo se ve mucho en las empresas, donde los empleados llegan con mucho impulso por hacer, por crear, y simplemente se les cortan las alas y se adoctrina para que todos sean iguales; al que piensa y actúa diferente se le cataloga como extraño, como pedante o como loco, y en ocasiones de esas cosas 'locas' son las que requerimos. Cuántas conferencias de innovación y emprendimiento se enfocan en los retos individuales, en gente famosa, inventores, artistas; grandes pensadores fueron relegados por pensar y actuar diferente, y a pesar de ser relegados dejaron un legado importante en la historia (Rodríguez, 2016), (Abío, 2017).

Igualmente, se debe tener en cuenta la transversalidad de los procesos tecnológicos en función de la educación y de encontrar significación en los procesos de aprendizaje, incluidos retos y nuevas formas de usar las aplicaciones tecnológicas en la educación (López-Savirón, 2016), (Fernández Mesa, 2016).

E1 Politécnico Grancolombiano es una institución universitaria ubicada en Bogotá, y el programa de Negocios Internacionales se encuentra adscrito a la facultad de ciencias Administrativas, Económicas y Contables. El programa de negocios internacionales cuenta con la siguiente malla: 


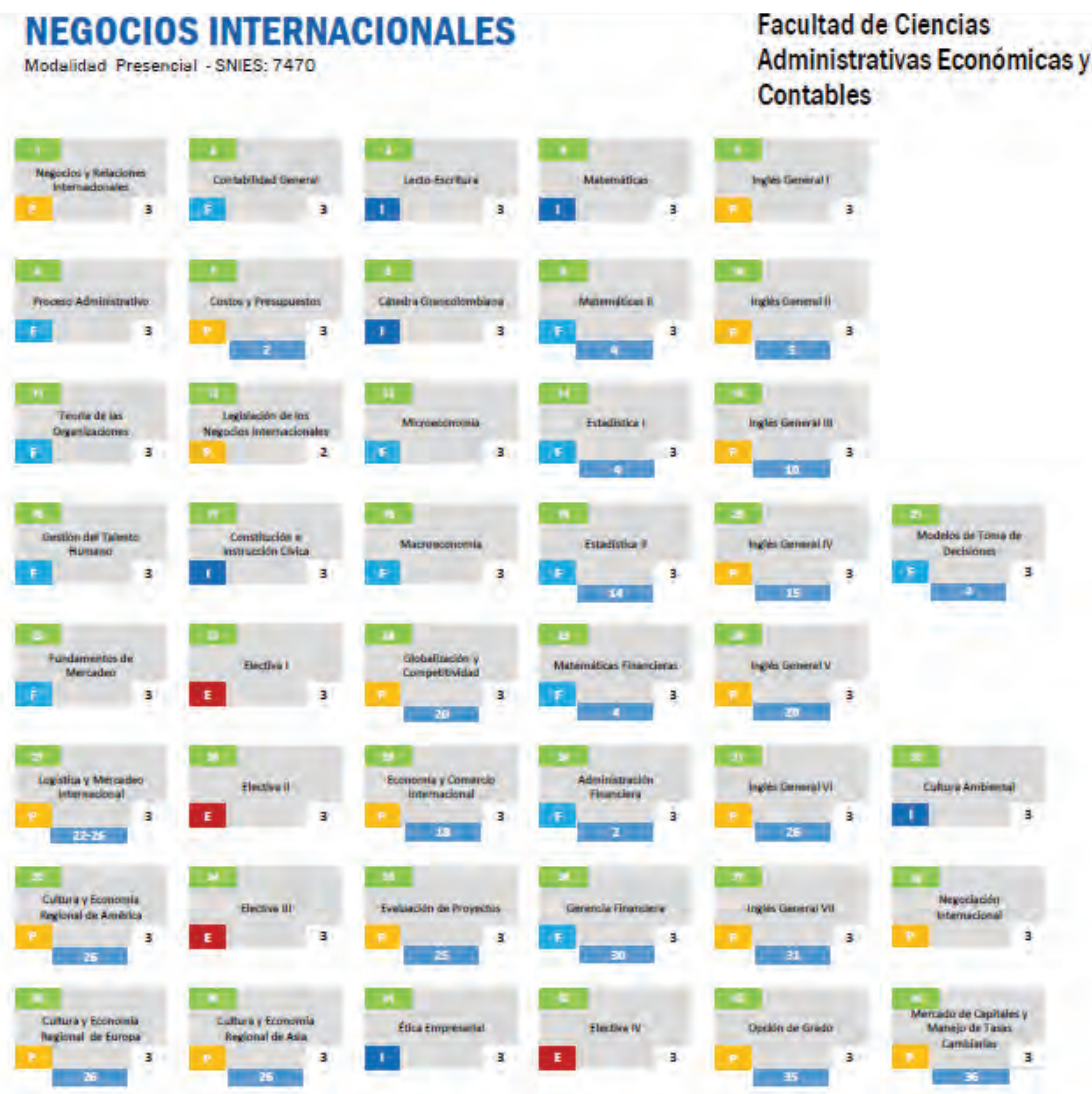

Ilustración 5: Plan de estudios Negocios Internacionales 2017.

La ventaja que tiene este programa es que cuenta con acreditación de alta calidad expedido por el Ministerio de Educación, por tanto, el programa permanece en constante cambio, evolución e innovación con el fin de crecer y reorganizarse de acuerdo con los perfiles y el mercado.

La aplicación del aula invertida en el área de Negocios internacionales se da en la asignatura de Negocios y Relaciones Internacionales, dirigida por la profesora Ángela Julieta Mora Ramírez. Dentro de la estrategia se empezó con una prueba piloto, con un curso de 46 estudiantes y otro de 39 estudiantes. Esta asignatura es electiva, por tanto existe un componente 
adicional: existen estudiantes no solamente de Negocios internacionales, sino de Mercadeo y publicidad, Medios audiovisuales, Comunicación social, Psicología, Derecho, Ciencia política e Ingeniería industrial, haciendo del piloto algo muy interesante, y más diversa la población.

Los estudiantes de Negocios internacionales son de primer semestre y llegan con toda la voluntad, a la vez con las falencias de la educación media. El reto es apropiarse de la tecnología y construir sobre lo planeado algo que realmente les genere interés a los estudiantes actuales.

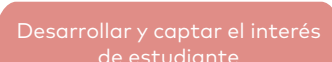
de estudiante
Generar procesos de auto estudio y disciplina
Complementar y realizar actividades didácticas diferentes
Desarrollar competencias y habilidades en cada estudiante
Aprovechar el aula virtual y las TIC para el desarrollo de las clases

Ilustración 6: Un gran reto pedagógico

Fuente: elaboración propia, 2017.

Ahora bien, la temática de la asignatura de Negocios y relaciones internacionales debe estructurar el proceso y enfocarlo en estudiantes que integren los negocios internacionales desde todas sus aristas. La idea inicial en el aula fue estructurar una metodología nueva relacionada con películas y enfocada a crear también equipos y competencias entre ellos de manera sana y dinámica.

En este orden de ideas, se empezó a desarrollar una estrategia para motivar a los estudiantes a conocer y hacer parte del pilotaje de aula inversa, una gran propuesta que integra escenarios propios de interés y, obviamente, una dinámica para el aula. 


\section{LA ESTRATEGIA Y LA MOTIVACIÓN EN LA APLICACIÓN DE AULA INVERSA}

Para el desarrollo de la experiencia se empezó no solo a aplicarla. Se hizo una documentación estricta con un gran estado del arte, que indicara la metodología más adecuada o la mezcla de procedimientos en el desarrollo y aplicación de la estrategia.

Teórico-Práctica
Escenarios internacionales a estudiar
Presencial y uso de componentes TIC

Ilustración 7: Descripción de la asignatura

Fuente: elaboración propi, 2017.

La interacción de una asignatura teórico- práctica incluye una metodología que realmente identifique en el estudiante una relación de lo teórico con lo práctico. La intención es desarrollar actividades donde se incluyan las TIC y el tiempo sea más aprovechado en las horas y encuentros en las aulas (Falco, 2017).

Por lo tanto, la idea es empezar con un gran viaje que asocie películas y unos títulos atractivos para el buen desarrollo de las clases.

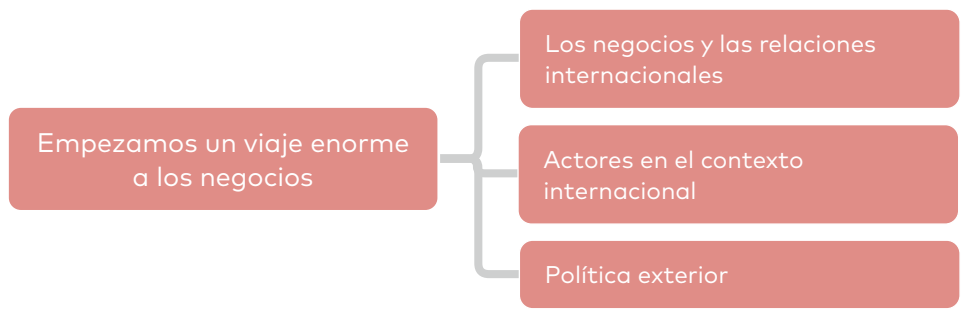

Ilustración 8: Núcleo Temático 1 Voyager Rouge one?

Fuente: elaboración propia, 2017.

En esta parte del sílabo o programa, desde su estructura, se encuentra el acercamiento inicial con los negocios internacionales y las relaciones internacionales: se enfoca en describir los negocios desde lo económico, lo político y lo social. 
Se maneja como un viaje, en la medida que empieza un reconocimiento de la evolución de los negocios a lo largo de la historia, su importancia y aplicación; con este viaje vienen también las herramientas metodológicas para el desarrollo y didáctica de la clase.

\section{CómO LO VAMOS A DESARROLLAR}

Fase inicial se plantea como propuesta de cambio cada mes representa una historia frente a una película adaptada a los negocios, conformación de los equipos de trabajo

En esta etapa se desarrolla dentro de la asignatura un ejercicio específico en estudio de caso desde el libro de Hill y con la herramienta Edmodo, YouTube para la organización con los equipos de trabajo mediante el uso de un concurso donde exista co- evaluación sobre el resultado diferencia entre negocios y relaciones, comercio, inversión extranjera directa

Desarrollo de los bloques y enfoca la didáctica a trabajo colaborativo y la realización de un plan exportador incluyendo análisis de mercado y verificación de oportunidades de negocios se apoya en videos de refuerzo lecturas pre establecidas, taller y seminario Alemán

Fase final desarrollo del plan establecer un blog y la presentación con videos debidamente soportada para la sustentabilidad del negocio de la empresa real, se efectúa con la empresa evidencia empírica y fuente primaria

llustración 9: Propuesta metodológica y estructural

Fuente: Propia

Dentro de las tecnologías a usar en el aula se encuentra activación de clases usando vídeos y material virtual, con el fin de que los estudiantes lleguen habiendo leído previamente los contenidos.

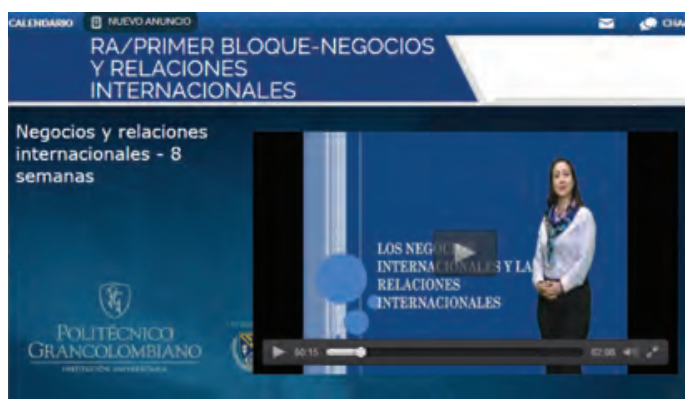


Con estos espacios de vídeos de no más de 20 minutos se puede interactuar en espacios de la misma clase y generar debate. De igual forma, mediante el uso de diferentes apps de teléfonos móviles se puede interactuar y mejorar el proceso de enseñanza- aprendizaje.

Como ejemplo está la aplicación Remind, que permite una comunicación directa con los estudiantes:

\section{Done}

\section{Keep communication in one place.}

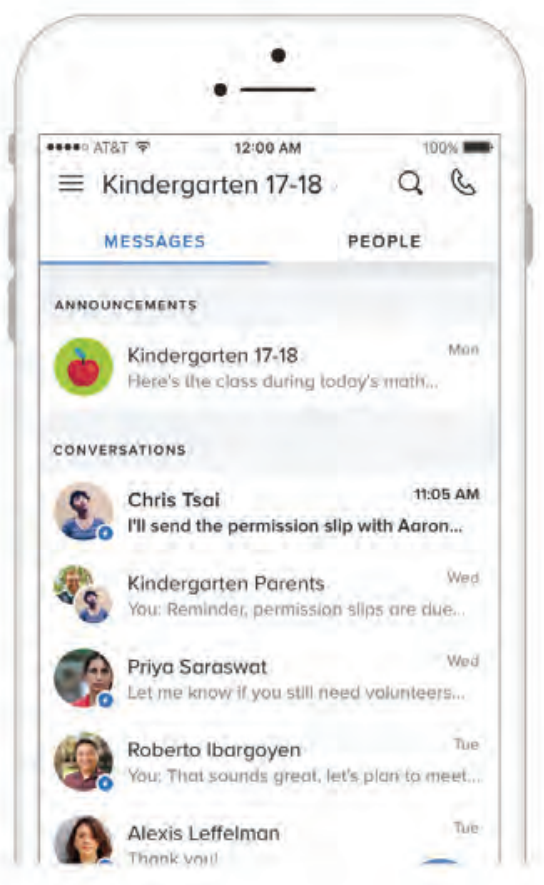

Con esta aplicación, al igual que la interacción en Moodle, la intención es que el estudiante no se aparte de la tecnología, por el contrario, se trata 
de activar la interacción, teniendo en cuenta las habilidades y competencias de nativos digitales de los estudiantes de esta generación.

Otro aplicativo con el que se puede jugar con fines didácticos es Capitales del mundo, que se puede ubicar en Google play o en el App store.

\section{Done}

\section{Capitals of the World}

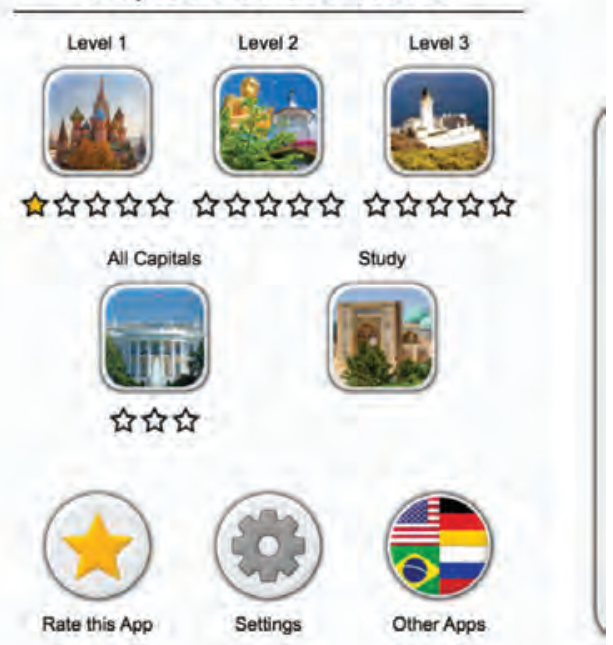

Estas aplicaciones hacen entretenida la hora de la clase pues se genera interacción y una dinámica mayor a la hora de realizar la clase.

Dentro de las actividades didácticas este primer corte que equivale al $30 \%$ realizamos énfasis en nuevas formas de tomar y ver la clase así: 


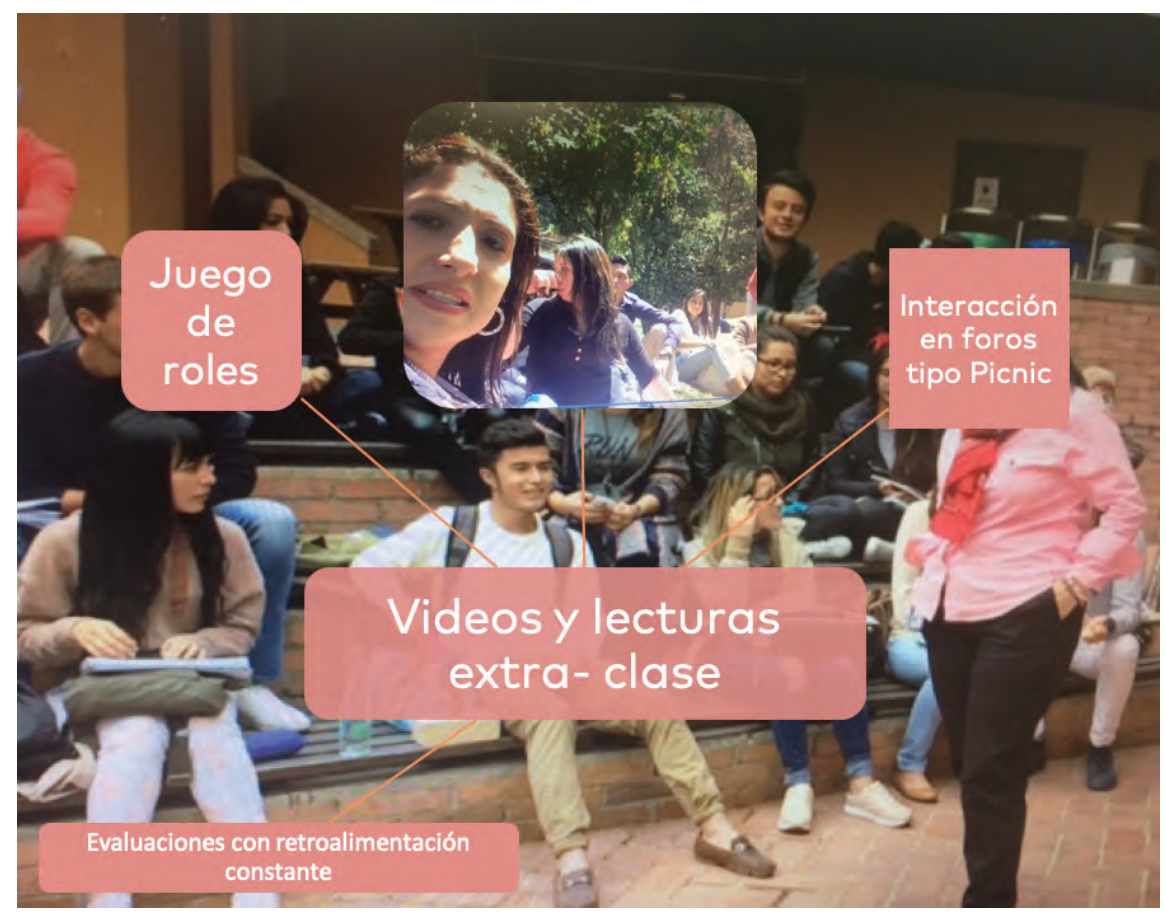

Ilustración 13: didácticas nuevas para enfoques que desarrollen las competencias.

La medición de los procesos va a desarrollarse en este corte de la siguiente manera: tabulación de notas, con el fin de verificar promedio ponderado en la aplicación de la metodología. Resultados del primer corte, tipo de medición: sobre la ponderación de evaluaciones del corte, se establece bajo criterio de pérdida y logro, determinando número por cada una de las notas, y verificando si la metodología impacta positivamente en las evaluaciones del grupo. 


\section{RESULTADOS PRIMERA MEDICIÓN}

\begin{tabular}{|c|c|c|c|c|}
\hline NOTAS & $\begin{array}{l}\text { NUMERO DE } \\
\text { ESTUDIANTES }\end{array}$ & PORCENTAJE & & \\
\hline 0.0 & 4 & $8,70 \%$ & & \\
\hline 1.2 & 1 & $2,17 \%$ & & \\
\hline 1.5 & 2 & $4,35 \%$ & & \\
\hline 1.7 & 2 & $4,35 \%$ & & \\
\hline 1.8 & 1 & $2,17 \%$ & & \\
\hline 1.9 & 2 & $4,35 \%$ & & \\
\hline 2.0 & 2 & $4,35 \%$ & & \\
\hline 2.1 & 1 & $2,17 \%$ & & \\
\hline 2.2 & 2 & $4,35 \%$ & & \\
\hline 2.3 & 3 & $6,52 \%$ & & \\
\hline 2.5 & 4 & $8,70 \%$ & & \\
\hline 2.8 & 1 & $2,17 \%$ & $54,35 \%$ & 25 \\
\hline 3.0 & 4 & $8,70 \%$ & & \\
\hline 3.1 & 1 & $2,17 \%$ & & \\
\hline 3.2 & 1 & $2,17 \%$ & & \\
\hline 3.3 & 2 & $4,35 \%$ & & \\
\hline 3.5 & 2 & $4,35 \%$ & & \\
\hline 3.9 & 1 & $2,17 \%$ & & \\
\hline 4.0 & 1 & $2,17 \%$ & & \\
\hline 4.2 & 4 & $8,70 \%$ & & \\
\hline 4.4 & 4 & $8,70 \%$ & & \\
\hline 4.5 & 1 & $2,17 \%$ & $45,65 \%$ & 21 \\
\hline $\begin{array}{l}\text { Total } \\
\text { general }\end{array}$ & 46 & $100,00 \%$ & $100,00 \%$ & 46 \\
\hline
\end{tabular}

Tabla 1: Medición del curso de Relaciones Internacionales

Fuente: elaboración propia (2017), apoyada con semilleros de investigación a cargo de las autoras. 
Es evidente que, de los 46 estudiantes con la aplicación de la metodología, el 54\% del grupo tuvo bajo rendimiento. Esto se debió a los siguientes factores:

En primer lugar, los estudiantes no comprenden suficientemente lo que leen, a pesar de que se notó habilidades potenciales en la competencia comunicativa oral, pues la primera evaluación fue un taller sustentado, pero en la competencia escrita de racionamiento y análisis se bloquearon y no construyeron un producto adecuado para el nivel exigido.

Es importante aclarar que entre las competencias que se estructuraron para evaluar se encuentran la comunicativa y la intelectual (por medio de la escritura), y la argumentativa como parte esencial de los procesos y dinámicas de crecimiento.

La metodología de aula inversa resulta nueva para ellos. Lo positivo es que cuando se dio la retroalimentación con el nuevo modelo, se vieron resultados y manifestaciones de reto hacia la asignatura en forma positiva: "profe, vamos a hacerlo, lo vamos a lograr"; esto es muy bueno desde la estructura pedagógica misma. En clase se les mostraron los resultados de las evaluaciones en gráfico:

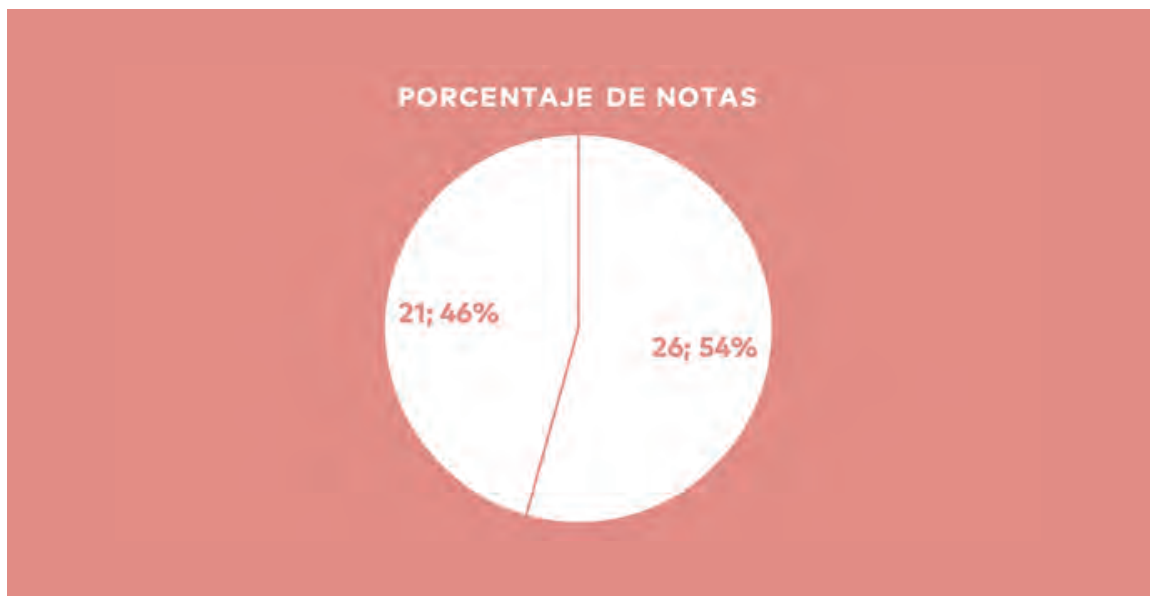

Grafica 2: resultados de pérdida

Fuente: elaboración propia (2017), con datos apoyados por semillero a cargo de las autoras. 
Esta eventualidad, desde la dinámica de la clase en la entrega de resultados, fue positiva en la medida que se mostró respuesta y, sobre todo, cuestionamiento. Como docente, la reacción de la profesora Mora fue: "estamos generando un cambio, se les mueve el piso".

Por su parte, del grupo de 39 estudiantes los resultados son los siguientes, para poder comparar posteriormente los dos grupos:

\begin{tabular}{|c|c|c|c|c|}
\hline Etiquetas De Fila & Cuenta De Estudiante & PORCENTAJE & & \\
\hline 0 & 2 & $5,13 \%$ & & \\
\hline 1.6 & 1 & $2,56 \%$ & & \\
\hline 2.4 & 1 & $2,56 \%$ & & \\
\hline 2.6 & 1 & $2,56 \%$ & & \\
\hline 2.7 & 1 & $2,56 \%$ & & \\
\hline 2.8 & 1 & $2,56 \%$ & 7 & $17,95 \%$ \\
\hline 3.0 & 4 & $10,26 \%$ & & \\
\hline 3.1 & 4 & $10,26 \%$ & & \\
\hline 3.2 & 1 & $2,56 \%$ & & \\
\hline 3.3 & 3 & $7,69 \%$ & & \\
\hline 3.4 & 1 & $2,56 \%$ & & \\
\hline 3.5 & 1 & $2,56 \%$ & & \\
\hline 3.6 & 2 & $5,13 \%$ & & \\
\hline 3.7 & 1 & $2,56 \%$ & & \\
\hline 3.8 & 1 & $2,56 \%$ & & \\
\hline 4.0 & 2 & $5,13 \%$ & & \\
\hline 4.1 & 2 & $5,13 \%$ & & \\
\hline 4.3 & 2 & $5,13 \%$ & & \\
\hline 4.4 & 2 & $5,13 \%$ & & \\
\hline 4.5 & 2 & $5,13 \%$ & & \\
\hline 4.6 & 1 & $2,56 \%$ & & \\
\hline 4.7 & 1 & $2,56 \%$ & & \\
\hline 5.0 & 2 & $5,13 \%$ & 32 & $82,05 \%$ \\
\hline Total general & 39 & $100,00 \%$ & 39 & $100,00 \%$ \\
\hline
\end{tabular}




\section{PORCENTAJE DE NOTAS}

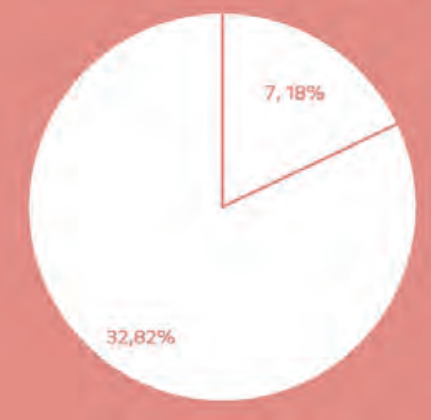

Gráfica 3: Porcentaje de pérdida y ganancia.

Fuente: semillero de investigación a cargo de las autoras, 2017.

Los estudiantes vienen de una formación memorista que solamente se expone con discusiones que se convierten en coloquiales. Lo bueno del ejercicio es que los estudiantes ya están cuestionando e interiorizando la necesidad de leer y ver los vídeos, de lo contrario, van a tener malos resultados; esto incluye una verificación del uso de la tecnología y las redes sociales de manera adecuada y centradas en la formación tal como los sustentan Fernández-Alonso (2015) y Castellanos Sánchez (2017).

De los dos grupos, en el más pequeño se dio una mejor actividad y desarrollo académico, pero aún hay falencias en temas de memoria y capacidad de análisis. Estas fallas se van a cubrir con más vídeos de apoyo y lecturas resumidas, con el fin de que el tiempo de trabajo en casa sea óptimo.

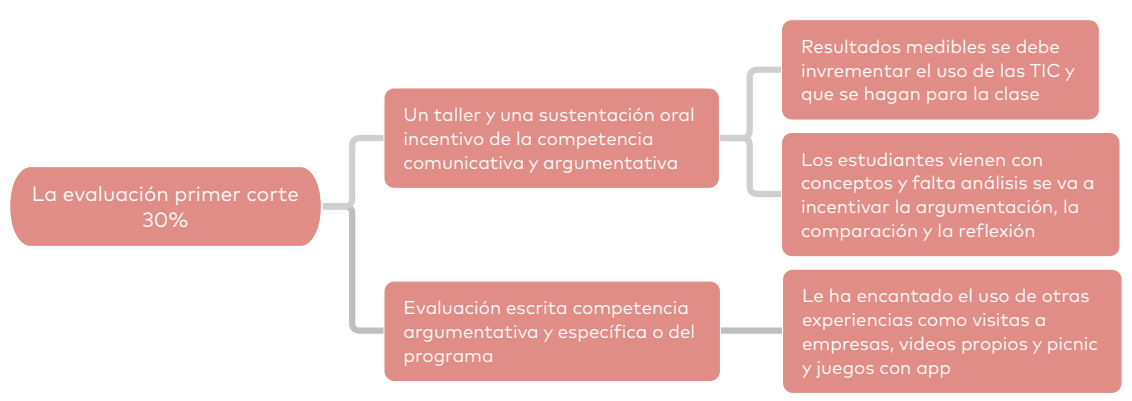

Ilustración 14: La experiencia desde la evaluación.

Fuente: elaboración propia, 2017. 
En el segundo corte académico se va a establecer desde las siguientes aristas, previo compromiso de los estudiantes acerca de qué ha sido lo más positivo y enriquecedor.

\section{LA GUERRA DE LOS CLONES, SEGUNDA FASE DEL PROCESO E IMPLEMENTACIÓN DE AULA INVERSA.}

Las empresas se han organizado de manera rápida y los países que vieron la oportunidad de crecimiento lograron desarrollo en su sistema nacional, el comercio y las regulaciones del estado; por otra parte, se dio la intervención, los malos manejos en los gobiernos y, al mismo tiempo, la búsqueda de organizar un sistema internacional.

Los países empiezan a competir de manera agresiva, como en la película La guerra de los clones, buscando el mercado.

Ante este escenario se presenta el jedi, que se asemeja a la hegemonía de los mercados que derriban las fronteras. Aquel desestabiliza escenarios ya creados y vulnera la convivencia entre los seres humanos. Las máquinas y las formas de negocio se muestran como estratégicas, y los seres humanos buscan maximizar ganancias a bajos costes.

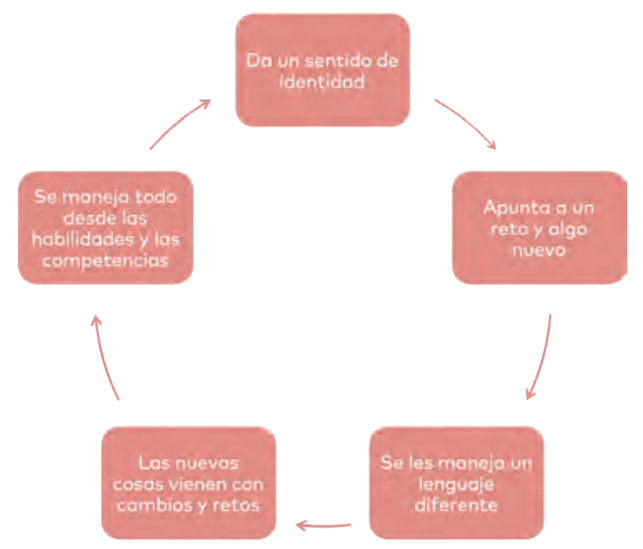

Ilustración 17: La asociación con una película 
De las alternativas que se empleen en el aula y la didáctica que se establezca allí, también mejora la conciencia y el uso de alternativas didácticas para el desarrollo y la mejora de los espacios de formación (Bakken et al., 2016), (Mateu, 2017).

La medición en la segunda fase se desarrolla mediante encuestas a los 85 estudiantes de los dos grupos, y revisar la adaptación y el desarrollo de la estrategia de aula inversa o invertida.

Apoyar la sesiones presenciales con TIC
Incrementar los temas y el uso de google académico
Usar retos y mayor énfasis en los temas

\section{ANÁLISIS DE RESULTADOS DE LA ENCUESTA FASE 2}

Fase final del proceso del pilotaje de aula inversa discusión y conclusiones

Esta fase se denominó El imperio contraataca. Cada situación del mercado se convierte en este momento en una oportunidad o amenaza, más aún si la empresa no es competitiva. Por tal razón, se va a enfatizar en la competencia descriptiva y de observación investigativa, trabajando en la empresa como tal en el sector, otorgando al estudiante una visión real de los procesos empresariales con fines de internacionalización.

La evaluación se hizo con rendimiento y seguimiento en las notas y en la aprobación final de los estudiantes de los dos cursos, de tal forma que pudiera generar acciones encaminadas a mejorar y construir una metodología válida para incrementar la calidad educativa en el programa de Negocios internacionales del Politécnico Grancolombiano. 
La finalidad de estas experiencias es, en definitiva, incrementar el rendimiento académico (Jancsó, 2017), (Hernández, 2017). La motivación en el aula es muy importante, en especial para promover el pensamiento crítico, como lo exponen en sus estudios Zacarías Munguía (2016), Villaplana (2016), Dreizzen (2016), (Cano Rodríguez (2017).

En esta fase se aplicaron dos instrumentos. Uno de ellos fue una encuesta en focus group tipo Likert validada con experto; la plantilla que se usó fue la siguiente:

Esta encuesta se realiza con fines educativos, responda cada una de las preguntas marcando con una $\mathrm{X}$ aquel criterio que considere correcto en el rango. (1 Total desacuerdo, 2 En desacuerdo, 3 De acuerdo y 4 Totalmente de acuerdo).

PREGUNTA

1. Los videos propuestos por la docente para ser vistos fuera del aula de clase han sido un apoyo en su proceso de formación.

2. La nueva metodología propuesta en el aula invertida lo ha beneficiado en su proceso de aprendizaje.

3. Con los temas vistos en los temas de Negocios y Relaciones Internacionales, considera que ha adquirido nuevas habilidades que le permitan ser aplicadas dentro y fuera de la clase.

4. Con la implementación del aula invertida se facilita la realización de los talleres y el parcial.

5. Los temas vistos en el aula invertida se pueden relacionar con la carrera que está cursando. 


\section{[138] Innovación educativa: nuevas metodologías y experiencias en el aula}

Análisis Esta prueba es una escala tipo Likert consta de 5 reactivos donde se pretende medir si el aula invertida ha beneficiado a los estudiantes en su proceso de formación, esta prueba está dirigida a estudiantes de diferentes carreras que estén cursando la asignatura de Negocios y Relaciones Internacionales de la jornada Diurna la cual consta de 2 grupos.

Ítem 1: $\quad$ El $72 \%$ de la población encuestada está totalmente de acuerdo que los videos propuestos por la docente han sido de gran apoyo para su formación concluyendo así que para la mayoría de estudiantes de los dos grupos han utilizado este recurso para una mejor comprensión de los temas vistos en clase.

Ítem 2: $\quad$ El 53\% de la población encuestada está totalmente de acuerdo que esta nueva metodología del aula invertida los ha beneficiado en su proceso de aprendizaje concluyendo así, que más de la mitad de los estudiantes pertenecientes a los dos grupos consideran que la nueva metodología es una manera innovadora de impartir clases y facilitar su aprendizaje.

Ítem 3: $\quad$ El $68 \%$ de la población encuestada está totalmente de acuerdo que ha adquirido nuevas habilidades que podrán aplicar dentro y fuera del aula de clases basándose en los temas vistos hasta ahora en la clase de negocios, llegando a la conclusión de que los estudiantes tienen presentes los nuevos conocimientos que han adquirido en esta clase y los llegan a aplicar en su diario vivir.

Ítem 4: $\quad$ El 53\% de la población encuestada considera que con esta metodología se les facilita más la realización de parciales y talleres concluyendo que esta metodología ha sido beneficiosa a la hora de evaluar su conocimiento.

Ítem 5: $\quad$ El $62 \%$ de la población encuestada considera que los temas vistos en la asignatura de Negocios puede estar relacionada con las distintas carreras que están cursando los respectivos estudiantes, concluyendo y corroborando que los temas vistos están siendo aplicados en otras áreas. 


\section{A MANERA DE CONCLUSIÓN}

Con el análisis de estos reactivos se logró concluir que la nueva metodología propuesta en el aula invertida es una excelente manera de impartir y recibir información, siendo un método más dinámico con el cual se facilita la comprensión de los temas vistos, a la vez que promueve su aplicación en las diferentes áreas de conocimiento, demostrando así lo polifacética que puede llegar a ser la asignatura de Negocios y relaciones internacionales.

En definitiva, la estrategia ha funcionado satisfactoriamente, el estudiante ha sido bien evaluado y ha dado enormes resultados de sus habilidades y competencias; los estudiantes han llevado sus conocimientos más allá de la teoría: por medio del análisis a la empresa han observado cómo funciona una compañía y de qué manera hay aplicación y practicidad.

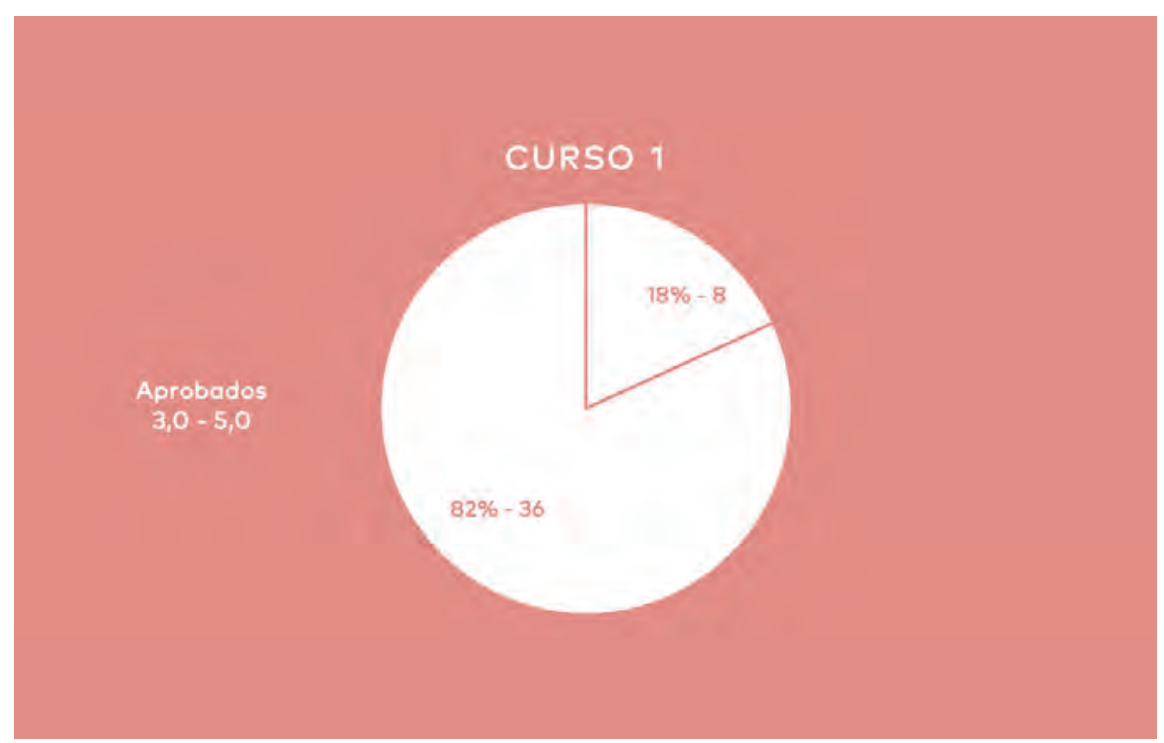

Ilustración 15: Resultados finales con notas, curso 1

Fuente: elaboración propia con apoyo del semillero de investigación a cargo de las autoras, 2017. Este dato es del curso de 44 estudiantes. 


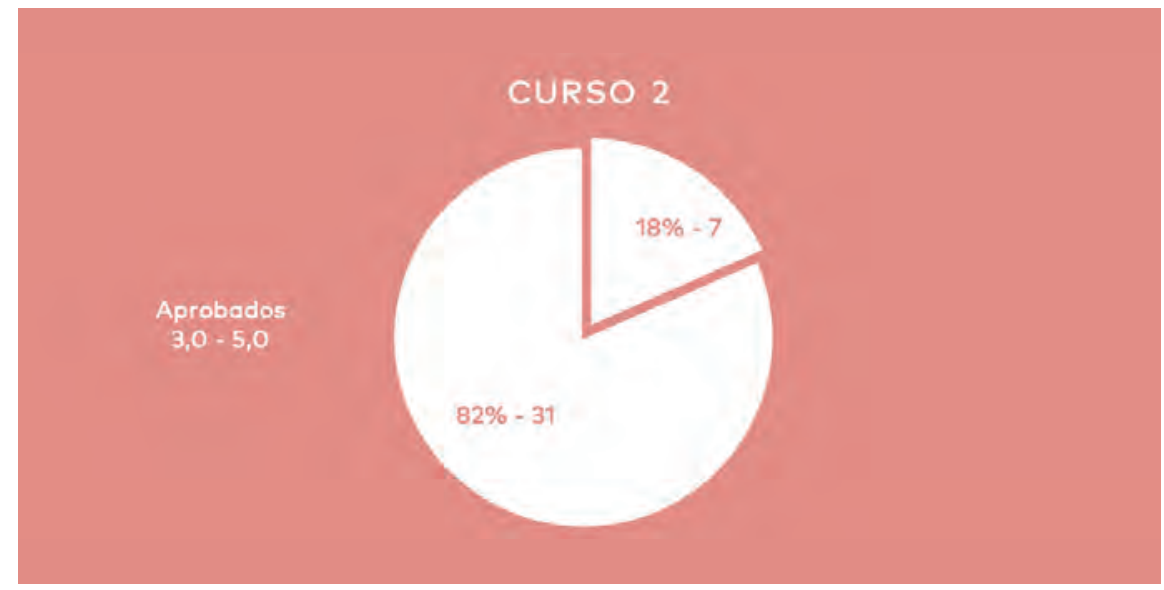

Ilustración 16: Resultados finales en notas curso 2

Fuente: elaboración propia con apoyo del semillero de investigación a cargo de las autoras, 2017. Este dato es del curso de 38 estudiantes.

Los dos cursos lograron superar con éxito la estrategia, llegando a una aprobación por encima del $80 \%$. Si bien esto representa una satisfacción enorme, queda un $20 \%$ en cada grupo que genera inquietud.

Este 20\% representa estudiantes que no culminaron su asignatura o que solo asistieron a los exámenes y no a las actividades adicionales: esto es un indicador que ahora les obliga a asistir a clase y a realizar todas las actividades en ella. Este 20\% demuestra que en ocasiones la motivación no es suficiente y que existen diversas dificultades personales, familiares, sociales, de aprendizaje, que no permiten captar su atención. De este porcentaje del 20\%, la mitad no superó el primer corte académico por problemas económicos, lo cual influye directamente sobre la deserción de los estudiantes de las aulas presenciales.

El exceso de laxitud con la que se trabaja en ocasiones no es positivo; el ejercicio evidencia que debe existir una creación de hábitos con retos, como se hizo con el 80\% en el que la motivación alcanzó un punto clave: estudiantes que lograron empezar a cuestionarse y a conectar las ideas con argumentos y capacidad crítica. El ejercicio se dio en competencias desde la argumentativa, la comunicativa y la específica, mostrando resultados no memorísticos. 
Ahora bien, cuando se verifica el $80 \%$ se sacan conclusiones positivas en cuanto a la forma de ver las diferentes habilidades de los estudiantes. En la última parte desarrollaron planes de negocio en empresas reales del sector del calzado, cuero y manufacturas, haciendo visitas a las empresas y, en general, revisando datos y comparando el sector con la teoría sobre internacionalizar una empresa.

Al ser una materia de tipo electivo, se empezaron a visibilizar grupos con áreas diferentes de conocimiento y, por tanto, con grupos mixtos en sus aportes y discusiones, lo cual fue un éxito, pues la transversalidad dio para que los estudiantes aprendieran desde sus áreas específicas acerca de cómo funciona una empresa del sector para su proceso de internacionalización.

Se hicieron aportes enriquecedores en relación con los negocios internacionales vistos desde el mercadeo, los medios audiovisuales, la administración de empresas, la psicología, el derecho, la ciencia política y la comunicación social.

Estudios como el de Reina Martínez (2017) proponen una visión diferente acerca de la transversalidad en el aula, y en este caso se piensa desde el aula inversa como una forma de llegar al estudiante, revisando sus competencias y habilidades, haciendo de la práctica una forma de conocimiento y haciendo de la teoría un aporte a la formación. Así, la innovación en las aulas de clase se ha desarrollado notablemente: se han descubierto estudiantes creativos para diseñar la imagen de las empresas, otros con dominio de vídeo y redes sociales, en fin, cada competencia se acrecentó de manera real.

Un ejercicio de transversalidad en el aula inversa -junto con ajustes particulares a la población objetivo como análisis del tiempo, de los hábitos, de la negociación misma, la ética y los recursos que nos hacen más humanos- debe llegar al punto clave del acercamiento con el estudiante. El valor del respeto, la aceptación del otro, decir las cosas de frente a tiempo y con diplomacia, son ejemplos clave de esto, tal como lo aborda Scavone (2017).

La transformación con esta estrategia de abordar al estudiante realmente funciona, la memoria se dejó de lado y los vídeos se convirtieron en algo esencial. El uso de la herramienta Remind también fue un éxito. Estas trasformaciones deben seguir dándose en las aulas de clase para empezar a 


\section{[142 ] Innovación educativa: nuevas metodologías y experiencias en el aula}

crear estrategias adaptadas a nuestra población, apoyándonos en las herramientas virtuales.
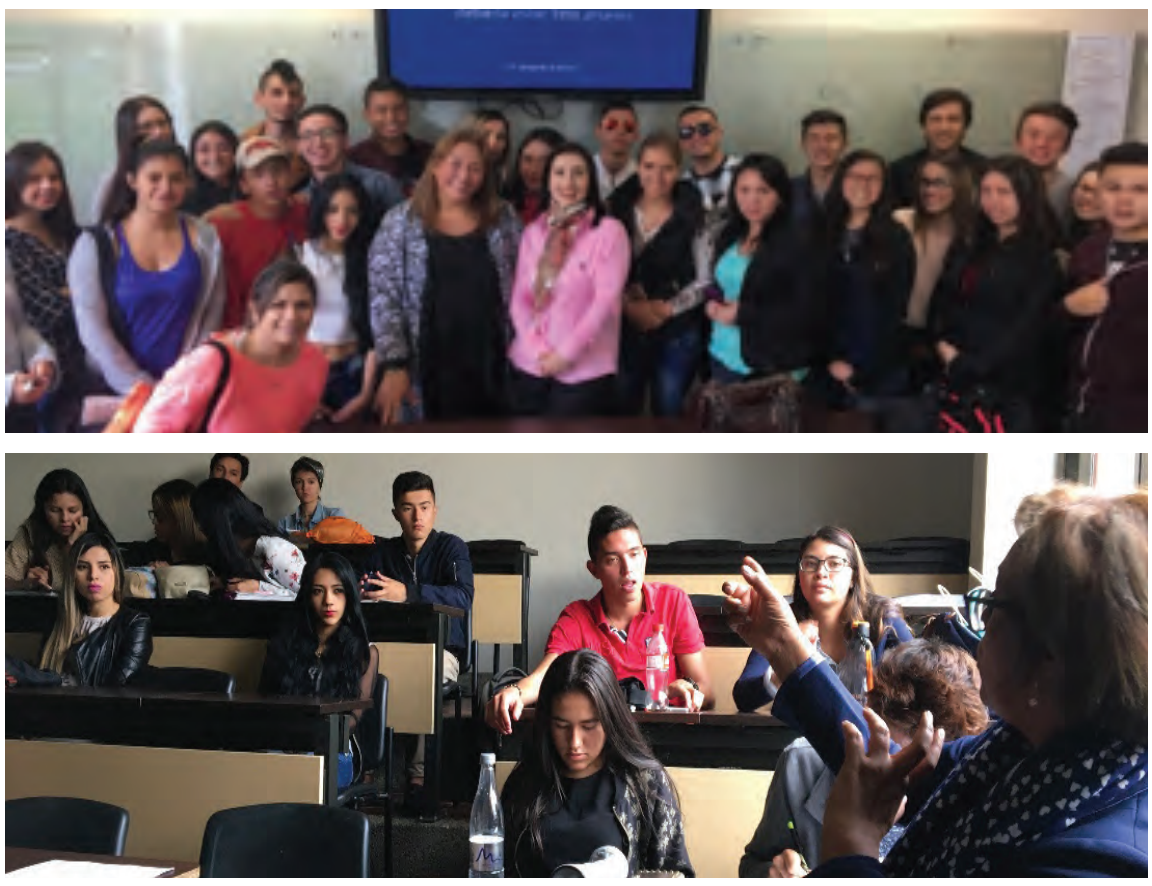

Ilustración 18: Registro fotográfico actividad final

Fuente: Propia

El acercamiento a cada estudiante se dio en mayor medida y realmente se aprecia un mejor nivel en términos de competencias y habilidades. El viaje no culmina aún: existen elementos para ajustar, desde el planteamiento inicial de Star wars como un apoyo en la intención de descubrir, de conocer, de apropiar imaginarios en función de la atención del estudiante, entusiasmarlo cada día para conocer acerca de los negocios internacionales. Por otro lado, como docente ha sido una experiencia enriquecedora, llevando al estudiante -desde la academia- a reconocerse, a cambiar, a adaptarse, a trabajar en equipo, a equivocarse, a hacer parte de la realidad que existe en el mundo laboral. 
E1 reto es importante: empezar a organizar situaciones de cambio donde el estudiante sea el actor principal, no solo llenar de datos, sino hacer que esta información sea útil, que tenga validez y aplicación en el mundo real.

\section{REFERENCIAS}

1. Aaron, B. (2014). Flip Your Classroom. Reach Every Student in Every Class Every Day. (págs. 1-107). Madrid, España.

2. Abío, G.. (2017). Laula invertida i l'aprenentatge en equip: dues metodologies per estimular l'alumnat repetidor. Revista d'Innovació Docent Universitària, $1-15$.

3. Aebli, H. (1998). Los factores de la enseñanza que favorecen el aprendizaje autónomo. Madrid, España: Narcea.

4. Albaladejo, C. (2013). Acerca de la utilidad del aula invertida . Recuperado de: https://web.ua.es/es/ice/jornadas-redes-2016/documentos/.../805139. pdf

5. Alcántara, A. (2007). Reencuentro. Análisis de Problemas Universitarios, (50), 21-27.

6. Alles, M. (2002). Dirección estratégica de recursos humanos: gestión por competencias. Buenos Aires, Argentina: Granica.

7. Alonso Castañón, M. (2007). "Los retos de la Educación Basada en Competencias para el diseño del perfil profesional: el caso de la Universidad Politécnica de San Luis Potosí". Ponencia presentada en el Congreso Mundial sobre las Competencias. Cali, Colombia. 
8. Álvarez Medina, L. (2005). "Evaluación y certificación de las competencias laborales en México. El caso de las dependencias del gobierno federal". Contaduría y Administración. Universidad Autónoma de México, (34).

9. Andión, M. (2007). Reencuentro. Análisis de Problemas Universitarios, (59).

10. Andrade Cázares, M. (2008). Un acercamiento al enfoque por competencias profesionales. Trabajo presentado en la Universidad de Guanajuato.

11. ANECA. (2009). Agencia Nacional de Evaluación de la Calidad y Acreditación. Recuperado de: www.aneca.es/estudios/estu_informes.asp

12. Angelini, L. (2012). Revista de Investigación en Educación DOI:10.13140/2.1.1533.5046. Integración de modelos pedagógicos en la formación de profesorado: La clase invertida y la simulación y juego, (10).

13. Arriola, M. (2007). Desarrollo de Competencias en el proceso de instrucción. Competencias, (23).

14. Barrera, J. (2008). La persona correcta en el lugar correcto. Revista Mundo Ejecutivo. Recuperado de: www.sld.cu/galerias/doc/sitios/infodir/la_persona_correcta_en_el_lugar_correcto.doc

15. Bericat, E. (1989). La integración de los métodos cuantitativo y cualitativo en la investigación social: significado y medida. Barcelona: Ariel.

16. Blasco, A. (2016). La clase invertida y el uso de vídeos de software educativo en la formación inicial del profesorado. Estudio cualitativo. @ tic. revista d'innovació educativa. (17). 
17. Bourdieu, P. (2016). La distinción: criterio y bases sociales del gusto. París: Taurus.

18. Buendía, A. (2007). Hacia una nueva sociedad del conocimiento: retos y desafíos para la educación virtual. México: Limusa.

19. Bunk, G. (1994). La transmisión de las competencias en la formación y perfeccionamiento profesionales de la RFA. Revista Europea, Formación Profesional, (10).

20. Cano Rodríguez, G. (2017). ConTIC aprendí: Aula invertida como modelo para promover el pensamiento crítico en estudiantes de grado noveno del Colegio Antonio García. Master's thesis. Universidad de La Sabana, 23-35.

21. Castellanos Sánchez, A. (2017). Nuevos modelos tecnopedagógicos. Competencia digital de los alumnos universitarios. Revista Electrónica de Investigación Educativa, (19).

22. Castro, M. (2007). Enfoques alternativos en la educación superior. México: I.T.E.S.M.

23. Del Pino, B., Prieto, B. y Prieto, A. (2016). Utilización de la metodología de aula invertida. Enseñanza y Aprendizaje de ingenieria de computadores, 1-9.

24. Díaz-Barriga, F. (2002). Estrategias docentes para un aprendizaje significativo. Una interpretación constructivista. México: McGraw Hill.

25. Dirube Mañueco, J. (2004). Un modelo de gestión por competencias: lecciones aprendidas. Barcelona. Gestión, (45). 


\section{[146] Innovación educativa: nuevas metodologías y experiencias en el aula}

26. Dreizzen, E. (2016). Proceso de implementación del nuevo entorno virtual de enseñanza y aprendizaje Moodle de la Facultad de Ciencias Médicas. UNLP. TE \& ET., (22).

27. Dugua, C. (2007). La cultura en el aprendizaje escolar. Elementos para una pedagogía dentro y fuera del aula. México: Trillas.

28. Falco, M. (2017). Reconsiderando las prácticas educativas: TIC en el proceso de enseñanza-aprendizaje. Tendencias Pedagógicas, (29).

29. Fernández López, J. (2005). Gestión por competencias. Un modelo estratégico para la dirección de Recursos Humanos. México: Prentice Hall.

30. Fernández Mesa, A. (2016). Valor pedagógico del repositorio común de conocimeinto para curso de dirección de empresa. Revista de Innovación Educativa, (9).

31. Fernández-Alonso, R. (2015). Homework and Performance in Mathematics: The Role of the Teacher, the Family and the Student's Background. Journal of Psychodidactics, (22).

32. Fernández-Mesa, A. (2016). Pedagogical value of a common knowledge repository for Business Management courses. @ tic. revista d'innovació educativa, (16), 39-47.

33. Gálvez, A. (2015). Uso del vídeo docente para la clase invertida: evaluación, ventajas e inconvenientes. Recuperado de: https://www.researchgate. net/profile/Alfonso_Rosa-Garcia/publication/266673438_Uso_del_video_docente_para_la_clase_invertida_evaluacion_ventajas_e_inconvenientes/links/570c9bb608aea660813b2c87.pdf

34. Gardner, H. (2005). Las cinco mentes del futuro. Un ensayo educativo. Barcelona: Paidós. 
35. Gardner, H. (2005). Mentes flexibles. El arte y la ciencia de saber cambiar. Barcelona: Paidós.

36. Griffiths, L. (2016). Implementación del modelo de aula invertida para el aprendizaje activo de la programación en ingeniería. Recuperado de: http:// sochedi2016.ufro.cl/wp-content/uploads/2016/10/SOCHEDI_2016_paper_54.pdf

37. Hernández, B. (2017). Impacto de la metodología "Aula Invertida" en el desempeño académico de alumnos universitarios en la materia Estadística Inferencial. Aplicaciones de la tecnología educativa en diversos ambientes de aprendizaje, (283).

38. Iglesias González, J. (2007). Evaluación de las competencias del personal de Tecnologías de Información, su importancia en México y las competencias que son necesarias desarrollar en nuestro país. México DF: Universidad de Querétaro.

39. Jancsó, K. (2017). ¿Cómo darle la vuelta al aula? El aula invertida y el uso de Edpuzzle y Powtoon en la enseñanza del español. Serie Didáctica, (1), 106-136.

40. Lacleta, S. (2015). Metodología de enseñanza inversa apoyada en b-learning y gestión del conocimiento. Revista de educación a distancia, (32).

41. Leupin, R. (2016). ¿Pedagogía activa o métodos activos? El caso del aprendizaje activo en la universidad. Revista Digital de Investigación en Docencia Universitaria, 16-27.

42. López-Savirón, P. (2016). El Flipped Classroom (Aula invertida) y su eficacia en la acción educativa. UNIR, 32. 
43. Luján-Mora, S. (2013). De la clase magistral tradicional al MOOC: doce años de evolución de una asignatura sobre programación de aplicaciones web. Revista de Docencia Universitaria REDU. Recuperado de: http://dx. doi.org/10.4995/redu.2013.5557, 279-300.

44. Mateu, M. (2017). Aula invertida: Experiència en el Grau d'Infermeria. Revista d'Innovació Docent Universitària, 115-123.

45. Miguélez, M. (2016). Validez y confiabilidad en la metodología cualitativa. Paradigma, (27), 7-33.

46. Mosquera Cucalón, W. (2012). Diseño de una propuesta didáctica para la enseñanza de sistema de dos ecuaciones lineales con dos incógnitas utilizando el método "Flipped Classroom" o aula invertida. Recuperado de: http://scielo.sld.cu/scielo.php?script=sci_arttext\&pid=S0864-21412016000300020

47. Politécnico Grancolombiano. (2017). Plan de estudios Negocios Internacionales. Recuperado de: http://poli.edu.co/content/negocios-internacionales-0

48. Prieto Lobato, J. (2017). “ Tecnologías de información y la comunicación en la docencia universitaria: una experiencia interdisciplinar e interuniversitaria”. Memoria Proyecto de Innovación Docente, 20-34.

49. Quecedo, R. y Castaño, C. (2002). Introducción a la metodologia de investigación cualitativa. Revista de Psicodidáctica Universidad del país Vasco, $1-36$.

50. Ramírez, L. (2017). El rol de la modelación para el fortalecimiento y adaptación del método aula invertida. Recuperado de: http://www.pedagogia. edu.ec/public/docs/Comision_2/el_rol_de_la_modelacion_para_el_fortalecimiento.pdf

51. Reina Martínez, S. (2017). Aportes de las TIC a proyectos transversales institucionales. Tesis de Maestría, Universidad de La Sabana, 21. 
52. Rodríguez, M. (2016). Tecnologías de la información y la comunicación. Un eje transversal para el logro de aprendizajes significativos. REICE, Revista Iberoamericana sobre Calidad, Eficacia y Cambio en Educación, (2).

53. Ruíz, J., Sánchez, J., y Sánchez, E. (2014). Flipped Classroom, una experiencia de enseñanza abierta y flexible. Recuperado de: https://riuma.uma.es/xmlui/bitstream/handle/10630/8431/RuizPalmero_SanchezRodr\%C3\%ADguez_SanchezRivas.pdf?sequence $=1$

54. Sánchez Rodríguez, J. (2014). Las clases invertidas: beneficios y estrategias para su puesta en práctica en la educación superior. Recuperado de: http://dspace.uma.es/ xmlui/handle/10630/7821

55. Scavone, G. M. (2017). La transversalidad de la ética en la enseñanza de las Ciencias Económicas. Anuario de Investigación USAL, (3).

56. Sobrino Morrás, Á. (2014). Aportaciones del conectivismo como modelo pedagógico post-constructivista. Propuesta educativa, 39-48.

57. Talbert, R. (2015). Inverting the Transition-to-Proof Classroom. PRIMUS, (13).

58. TEC. (2014). Aprendizaje invertido. Observatorio de educación TEC de Monterrey, 1-29.

59. Vidal, M. y Morales, V. (2016). Aula invertida, nueva estrategia didáctica. Búsqueda temática digital Scielo, 1-11.

60. Villaplana, E. (2016). Aplicando la metodología Flipped-Teaching en el Grado de Ingeniería Informática. Una experiencia práctica, (12).

61. Zacarías Munguía, V. (2016). Relación entre la metodología flipped classroom y el aprendizaje de alumnos en la universidad continental mediante el uso de TIC. PENZA, 23-50. 